\title{
Banco de Dados na Educação Profissional: um Estudo de Caso à Luz da Teoria da Aprendizagem Significativa
}

\author{
João Silvestre Franco \\ joao.franco@ifba.edu.br \\ Instituto Federal da Bahia, Campus Santo Amaro \\ Santo Amaro, Bahia
}

\author{
Jorge Costa Leite Júnior \\ leitejr@ifba.edu.br \\ Instituto Federal da Bahia, Campus Santo Amaro \\ Santo Amaro, Bahia
}

\begin{abstract}
RESUMO
Este trabalho apresenta um estudo de caso realizado na disciplina Banco de Dados, numa turma de um curso técnico em Informática na modalidade integrada. Com o objetivo de investigar os processos de ensino e aprendizagem na disciplina, sob a luz dos pressupostos da teoria da aprendizagem significativa, o estudo abordou as seguintes questões: 1) Como a relação entre hierarquia conceitual e organização do ensino na disciplina e a matriz curricular do curso influenciam elaboração de estratégias subjetivas de aprendizagem? 2) Como as relações com a instituição, o curso, o professor e a turma podem contribuir (ou não) para uma aprendizagem significativa na disciplina? Para isso, como instrumentos de coleta de dados, foram adotados observações diretas e participantes, questionário e entrevista semi-estruturada. Os resultados reforçaram a importância de uma abordagem de ensino recontextualizada para educação profissional e da atenção às relações docente e discente, ao currículo e ao contexto social por uma aprendizagem não-mecânica. Concluiu-se que a organização e os métodos de ensino e os instrumentos de avaliação relacionados devem ser pensados a partir de uma hierarquia conceitual e visando a integração dos componentes curriculares são essenciais para a promoção de uma aprendizagem significativa em banco de dados.
\end{abstract}

\section{PALAVRAS-CHAVE}

aprendizagem significativa, banco de dados, educação profissional e tecnológica, ensino médio integrado

\section{INTRODUÇÃO}

$\mathrm{O}$ atual momento histórico, fortemente marcado pela presença das tecnologias digitais de informação e comunicação no cotidiano, refletem o aumento da necessidade de armazenamento, gerenciamento e uso adequado dos dados. Neste sentido, a abordagem das tecnologias em bancos de dados nos currículos de Computação em cursos técnicos e superiores é retrato do momento histórico e do crescimento dessa demanda.

Embora a organização do currículo vise a introdução não traumática de novos conhecimentos [2], muitas vezes, os estudantes

${ }^{*}$ Orientador. Doutor em Educação e Contemporaneidade. Professor titular do IFBA/Campus Santo Amaro.

Fica permitido ao(s) autor(es) ou a terceiros a reprodução ou distribuição, em parte ou no todo, do material extraído dessa obra, de forma verbatim, adaptada ou remixada, bem como a criação ou produção a partir do conteúdo dessa obra, para fins não comerciais, desde que sejam atribuídos os devidos créditos à criação original, sob os termos da licença CC BY-NC 4.0.

EduComp'21, Abril 27-30, 2021, Jataí, Goiás, Brasil (On-line)

(C) 2021 Copyright mantido pelo(s) autor(es). Direitos de publicação licenciados à Sociedade Brasileira de Computação (SBC). têm dificuldade de transferir o que aprendem em um contexto para outro contexto ou situação, porque os conhecimentos são adquiridos de forma mecânica ou quase mecânica [15]. Assim, promover a integração entre o conhecimento disciplinar e o currículo direcionado a estudantes de múltiplas idades e saberes prévios - um processo de recontextualização [28] - é um desafio.

Partindo da observação dos fenômenos educativos na disciplina Banco de Dados, alocada no $3^{\circ}$ ano do curso técnico em Informática integrado ao ensino médio do Instituto Federal de Educação, Ciência e Tecnologia da Bahia - IFBA, Campus Santo Amaro, percebemos que, mesmo com os esforços em confrontar conceitos correlatos das disciplinas estudadas nas séries anteriores, os estudantes apresentavam dificuldades na aquisição dos conhecimentos organizados na disciplina - a transferência de contexto que mencionamos acima.

Diante destas percepções, neste trabalho, propusemos a análise de elementos que compõem os processos de ensino e aprendizagem nesta disciplina, no âmbito da formação profissional do técnico em Informática. Para tanto, refletindo as especificidades do contexto e dos sujeitos envolvidos, sob a luz da teoria da aprendizagem significativa, estabelecemos como questões de pesquisa (QP):

(1) Como a relação entre hierarquia conceitual e organização do ensino na disciplina e a matriz curricular do curso influenciam elaboração de estratégias subjetivas de aprendizagem?

(2) Como as relações com a instituição, o curso, o professor e a turma podem contribuir (ou não) para uma aprendizagem significativa na disciplina?

Para abordar essas questões, na seção 2, trazemos trabalhos anteriores que tratam de ensino e aprendizagem em banco de dados, ao passo que na seção 3, apresentamos os pressupostos teóricos que fundamentaram a pesquisa. Na sequência, a seção 4 traz as concepções metodológicas, a caracterização dos participantes e dos instrumentos e processos de coleta de dados adotados. Posteriormente, na seção 5 , discutimos os fatores que contribuíram ou dificultaram a aprendizagem no contexto da disciplina no período investigado. Finalmente, na seção 6, tecemos as considerações finais e os trabalhos futuros.

\section{TRABALHOS RELACIONADOS}

Nesta seção, selecionamos trabalhos prévios sobre aspectos pedagógicos como estratégias de ensino, articulação de teoria e prática e recursos digitais no ensino e aprendizagem de banco de dados.

Rodriguez et al. (2016) descrevem uma oficina cujo público foram estudantes do sexo feminino do ensino médio, com o propósito de provocar a curiosidade sobre a Computação. Os autores e as autoras selecionaram tópicos sobre banco de dados, foco da oficina, elaboraram material de ensino integrando estudantes de graduação e pós-graduação e estimularam o estudo de tópicos avançados [20]. 
Considerando as dificuldades dos estudantes na articulação entre teoria e prática, Martinhago et al. (2014) apresentam uma experiência de ensino com a metodologia da Computação Desplugada na disciplina Banco de Dados, em um curso de Sistemas de Informação. Para as autoras e o autor, conforme o relato, comparadas à abordagem tradicional de ensino, centrada em aulas expositivas, as atividades aplicadas contribuíram para o aumento de interesse, atenção e participação dos estudantes [12].

Para a promoção de uma aprendizagem ativa na disciplina Banco de Dados no bacharelado em Sistemas de Informação, Castro e Siqueira (2018) relatam o uso de QR Code como recurso pedagógico. Neste trabalho, os estudantes receberam a tarefa de encontrar e agregar informações relacionadas ao modelo conceitual e ao modelo físico, como tabelas, atributos, relacionamentos e SQL, inseridas nos códigos QR, para solucionar um problema proposto [4].

Josko (2020) traz uma experiência de ensino baseada em problemas, intercalando aulas expositivas com atividades práticas, com foco no desempenho dos bancos de dados. Para o autor, pela necessidade atenção de aspectos como restrições de tempo e características dos modelos de dados, a concepção de situações-problema foi a parte mais difícil do projeto, tanto que, em alguns casos, não gerou um cenário valioso para análise [10]. Além disso, a avaliação do processo também foi complicada, dados os erros em diferentes níveis apresentados pelos estudantes na abordagem.

Saindo da linha de práticas, trazemos a experiência de um jogo digital criado como recurso auxiliar para melhoria e inovação nas práticas pedagógicas na disciplina de Modelagem de Dados da graduação em Análise e Desenvolvimento de Sistemas [24]. Outro caso é o TreineBD [7], chatbot "monitor da disciplina de banco de dados”, que promove um diálogo a partir de regras predefinidas pelos criadores e destaca-se pelo feedback rápido - um gap do ensino numa abordagem tradicional -, contribuindo para a aprendizagem a partir do direcionamento dos estudos do interlocutor.

Em relação aos trabalhos apresentados acima, relacionados a banco de dados, de modo geral, nossa pesquisa assemelha-se ao destacar o papel e as necessidades dos estudantes nos processos de aquisição do conhecimento. Difere-se, porém, no nível e modalidade de ensino - ensino médio integrado à educação profissional e tecnológica -, em conjunto com a abordagem teórica, fundamentada na teoria de aprendizagem significativa. Embora outras publicações também sejam fundamentadas nesta teoria, como em [1, 6, 23, 23, 29], estão relacionadas a outros campos da Computação.

\section{FUNDAMENTAÇÃO TEÓRICA}

Como apontamos na seção 1, este trabalho parte de percepções das dificuldades dos estudantes na disciplina Banco de Dados. Encontramos na teoria da aprendizagem significativa a base teórica para investigar, sobretudo na perspectiva dos estudantes, o processo de construção de significados em referência aos conteúdos da base tecnológica de tal disciplina e os impactos no processo na aquisição do conhecimento.

Um dos problemas observados no curso técnico integrado no cenário investigado - no âmbito desta pesquisa, especificamente, a disciplina Banco de Dados - é a dificuldade de transferir conceitos e proposições apresentados em um cenário específico para outro contexto. Para Novak (2002), p. 552, tradução nossa), essa "alta situatividade" é causada por uma aprendizagem mecânica ou quase mecânica e conduzem a "uma transferência limitada ou falha de conhecimento" [15].

Na contramão da aprendizagem mecânica, uma aprendizagem significativa resulta na modificação tanto de uma informação adquirida, quanto das informações já presentes na estrutura cognitiva ${ }^{1}$, que são atreladas ao novo material, conforme Ausubel (2000). Esse processo, denominado ancoragem, consiste no desenvolvimento de novos significados para novas informações, conceitos e proposições com base em âncoras mentais que o aprendiz já possui [2].

Nesta perspectiva, o conhecimento é resultante da combinação de conceitos presentes na estrutura cognitiva, que formam uma rede de declarações ou proposições, dependente dos esforços que o indivíduo faz para integrar tais conceitos [15]. Aprender, portanto, consiste num processo de transformação do conhecimento, ao invés de uma atitude externa e perceptível [21].

Em suma, conforme a teoria de Ausubel, a aprendizagem significativa difere-se da aprendizagem mecânica:

- Aprendizagem significativa: ocorre uma interação produtiva entre dados, informações e conhecimentos já existentes na estrutura cognitiva do aprendiz e novos materiais. Nesse processo, ideias, conceitos e proposições pré-existentes são modificados e atualizados, ganham novos sentidos a partir da interação com novos materiais [2];

- Aprendizagem mecânica: as conexões estabelecidas entre os conhecimentos prévios e os novos conteúdos acontecem de forma arbitrária, literal e não substantiva $[2,11]$.

Quando a aprendizagem é, de fato, significativa, o processo de "reaprendizagem" de uma informação esquecida é mais fácil, assim como aprender conteúdos relacionados [21]. Como na aprendizagem de novos materiais o conhecimento já existente na estrutura cognitiva também é modificado, amplia-se a capacidade de agregar novas informações semelhantes na estrutura cognitiva, de forma que a aprendizagem progride em outros contextos e ocasiões [11].

São condições indispensáveis para que haja aprendizagem significativa [11,16]: 1) deve haver significado lógico, estruturado e organizado de modo não-aleatório ou fortuito; 2) significado psicológico, ou seja, as informações precisam ser relevantes e estar relacionadas a conhecimentos prévios e expressivos, cuja relação acontece de forma diferenciada para cada um; e 3) o estudante precisa estar disposto a ter uma aprendizagem significativa, estabelecendo conexões entre o que já sabe e o que deseja aprender disposição favorável.

Não basta apenas haver as correspondências lógico-conceituais do conteúdo curricular, é preciso que o estudante tenha a intenção de aprender significativamente, conectando os conhecimentos relevantes pré-existentes na estrutura cognitiva com os novos conhecimentos para a construção de novos significados [15]. Deste modo, a aquisição do conhecimento pode ocorrer das seguintes maneiras:

- Aprendizagem por recepção: ocorre por meio da exposição do conteúdo "na forma de uma proposição substantiva

\footnotetext{
${ }^{1}$ Segundo Moreira (2011, p. 19), na ótica da teoria da aprendizagem significativa, estrutura cognitiva trata-se de um construto que faz referência "a uma área específica de conhecimentos ou a um campo conceitual, um complexo mais amplo de conhecimentos".
} 
ou não-problemática”, de modo que não exige a descoberta, mas a compreensão e a lembrança do que é apresentado "em sua forma final, acabado" $[2,11]$. É essencialmente associada à linguagem, enquanto meio de transmissão e troca [16].

- Aprendizagem por descoberta: em vez de apresentado em sua forma final pelo professor, o conteúdo deve ser aprendido por meio da descoberta, de modo que, para Ausubel (2000, p. 46), antes de internalizá-lo, o estudante precisa recompor um grupo de informações ou modificá-las para gerar um artefato esperado ou encontrar uma conexão meio-fim equivocada, antes de incorporá-lo à estrutura cognitiva $[2,11]$.

Para Ausubel, grande parte dos assuntos aprendidos na escola são aprendidos por recepção, ao passo que problemas do dia a dia são solucionados por descoberta. Ao mesmo tempo, o conhecimento aprendido por recepção é empregado na solução de problemas cotidianos, ao passo que, em sala de aula, atividades baseadas em solução de problemas têm o intuito de testar o entendimento e "aplicar, estender, integrar e avaliar o conhecimento do assunto" [2].

Cada forma tem papéis diferentes no desenvolvimento intelectual e cognitivo, cujas circunstâncias determinam se a aprendizagem, seja por recepção ou por descoberta, é mecânica ou significativa. Assim, técnicas expositivas podem gerar uma aprendizagem significativa e métodos baseados em resolução de problemas podem resultar numa aprendizagem mecânica (e vice-versa) [2].

A partir dos 3 anos de idade, a aprendizagem passa a ocorrer, principalmente, por recepção, por meio de questionamentos sobre relações entre novos conceitos e proposições e os que já estão presentes na estrutura cognitiva - adquiridos do nascimento até o terceiro ano da criança, inicialmente, por descoberta, mediante a distinção de "padrões ou regularidades em eventos ou objetos", relacionadas com "as mesmas regularidades rotuladas por pessoas mais velhas com palavras ou símbolos" (Novak and Cañas, 2006, p. 3) [16]. Assim, a linguagem torna-se um elemento importante no processo de aquisição do conhecimento.

Deste modo, ao analisar ensino e aprendizagem em um espaço educativo, importa-nos as relações sociais entre os pares, em que a linguagem é a ponte para a interação e intermediação entre os sujeitos, especialmente, os mais experientes, cuja troca contribui fortemente para aquisição e domínio de valores, conhecimentos, técnicas e comportamentos [19]. Neste sentido, de acordo com Moreira (2011, p. 61), "a chave da compreensão de um conhecimento, de um conteúdo, ou mesmo de uma disciplina é conhecer sua linguagem”.

$\mathrm{Na}$ ótica sociointeracionista de Vygotsky (2000, p. 332), "a aprendizagem é possível onde é possível a imitação” [26]. Ao favorecer a reconstrução (interna) do que é percebido pelo indivíduo externamente, a imitação torna-se uma via para o aprendizado, um meio de entendimento do sujeito [19]. Neste sentido, compreendemos a imitação, a partir da exposição de conteúdos, é um caminho para uma aprendizagem por recepção.

A diversidade, enquanto parte da essência do ambiente escolar, é um elemento importante para a aprendizagem e, no tocante à interação social, influi nas atitudes, nas escolhas, nas vivências, no progresso e nos conhecimentos que os sujeitos trazem, além de ampliar as oportunidades de apoio mútuo, confrontos de ideias e consequente expansão das aptidões individuais [19]. Nesta interação, por meio da linguagem - verbal ou não -, ocorre também o compartilhamento e a negociação de significados, estabelecidos pelas pessoas - não pelas coisas ou acontecimentos [14].

Além desses elementos, Ausubel reconhece que a estrutura cognitiva de cada indivíduo é pautada numa organização hierárquica e subjetiva de conceitos, ideias e proposições, que permitem a proposição de materiais potencialmente significativos [2]. Esta organização ocorre em função do nível de abstração e generalização, cujas conexões entre os diferentes conceitos formam uma teia conceitual que define a complexidade tais conhecimentos [21].

A sequência dos conteúdos a serem tratados, portanto, necessariamente tem que ser pautada em amostras palpáveis, e basear-se numa hierarquia conceitual, cujos pontos de partida devem ser conceitos mais abrangentes, fundamentais e inclusivos, passando por conceitos intermediários na caminhada em direção aos mais aprofundados e especializados [11].

Por fim, um último conceito que destacamos são os organizadores prévios, conforme Sala and Gõni (2000, p. 236), "materiais introdutórios que se apresentam antes do novo material de aprendizagem, para criar e/ou mobilizar inclusores pertinentes" [21], com o intuito de proporcionar uma aprendizagem mais ativa e mais rápida, atuando como uma ponte entre o que os estudantes já sabem e o que precisam saber [2]. Logo, são possíveis organizadores prévios, segundo Moreira (2011): "um enunciado, uma pergunta, uma situação-problema, uma demonstração, um filme, uma leitura introdutória, uma simulação" [14].

\section{PERCURSO METODOLÓGICO}

A pesquisa, com abordagem qualitativa e cunho exploratório, consiste num estudo de caso, realizado no período de agosto de 2018 a maio de 2019, durante três unidades letivas. Para assegurar a confiabilidade e validade da pesquisa, empregamos a triangulação de fontes, métodos e instrumentos de coleta de dados. Os dados foram coletados no âmbito de uma pesquisa para trabalho de conclusão do curso de Licenciatura em Computação.

\subsection{Caracterização dos participantes}

Os participantes foram 26 estudantes do $3^{\circ}$ ano do ensino médio integrado ao curso de Informática, com idades entre 16 a 19 anos, oriundos de diversas cidades do Recôncavo Baiano, Região Metropolitana de Salvador (RMS) e Portal do Sertão: Santo Amaro (38\% ou 10/26), Itapema (9\% ou 2/26), Saubara ( $11 \%$ ou 3/26), São Francisco ( $11 \%$ ou $3 / 26)$, Cachoeira ( $15 \%$ ou $4 / 26$ ), Cabuçu ( $4 \%$ ou $1 / 26)$, Oliveira dos Campinhos (4\% ou 1/26), Amélia Rodrigues ( $4 \%$ ou 1/26) e São Félix ( $4 \%$ ou 1/26); seis dos estudantes da turma (23\%) repetiram uma das séries do ensino médio no IFBA/Campus Santo Amaro entre os anos letivos de 2014 e 2017. 69\% (ou 18/26) foram estudantes do sexo feminino. Todos os estudantes cursaram a disciplina de Algoritmos em linguagem Java.

Os dados de origem e faixa etária dos participantes são importantes para a compreensão de algumas questões abordadas ao longo da pesquisa: presença e participação nos atendimentos ${ }^{2}$ e aulas da disciplina, além de motivações e limitações pessoais.

${ }^{2} \mathrm{O}$ atendimento (ao estudante) consiste numa atividade de apoio ao ensino e fazem parte da carga horária docente. 


\subsection{Caracterização da disciplina}

No curso técnico integrado em Informática do IFBA/Campus Santo Amaro, a disciplina Banco de Dados faz parte do $3^{\circ}$ ano, contando com uma carga horária total de 68 horas ( 80 horas-aula). A disciplina contempla a competência ASICP07 - Projetar, modelar e implementar esquemas de armazenamento, acesso e visualização de dados [5], do "Currículo de Referência para o Curso Educação Profissional Técnica de Nível Médio em Tecnologia e Computação" do Centro de Inovação para a Educação Brasileira (CIEB, 2020).

O plano de ensino é organizado de forma semelhante à ordem estabelecida nos livros e manuais técnicos da área. Nas figuras 1 e 2 trazemos representações esquemáticas da organização lógica dos conteúdos fundamentais na disciplina Banco de Dados, a partir das definições trazidas no plano de curso e estruturados seguindo uma hierarquia conceitual; empiricamente, permite, ainda, visualizar como a organização dos conteúdos é semelhante aos livros utilizados nos cursos superiores.

4.2.1 Organização e métodos de ensino. Na introdução dos conceitos essenciais, são aplicados exercícios manuscritos no papel e, conforme avançam na hierarquia conceitual, passa-se a utilizar o BR Modelo ${ }^{3}$ e, após os conceitos de generalização e especialização do modelo ER expandido, introduz-se o uso do MySQL Workbench $^{4}$, que permanece ao longo de todo o ano letivo.

A unidade I inicia com a abordagem de sistemas de arquivos e sistemas gerenciadores de banco de dados (SGBD). Em seguida, são trabalhados todos os tópicos referentes à modelagem de dados: o modelo conceitual entidade-relacionamento (ER), generalização e especialização (do modelo ER estendido), normalização e restrições de integridade, modelagem de sistemas comerciais comuns e refinamento de modelos de dados. O final da unidade I é marcado pela transição da modelagem conceitual para o modelo físico - o "Mapeamento do Modelo Entidade-Relacionamento para o Relacional”.

Entre as unidades I e II - geralmente, com previsão para a unidade II, conforme ilustra a figura 2 - são abordados os comandos de DDL para criação, exclusão e alteração da estrutura de tabelas. Dando continuidade aos conteúdos essenciais, na unidade II foca na DML: inserção, exclusão, atualização e consultas básicas, ordenação e funções de agregação. Outros tópicos, como ferramentas CASE para construção de consultas e modelos, são trabalhados transversalmente desde a introdução do MySQL Workbench.

A unidade III foca nas consultas avançadas com junções de tabelas (INNER JOIN, LEFT e RIGHT OUTER JOINs), visões (SQL VIEWS), subconsultas, procedimentos e funções (objetos armazenados). Posteriormente, na unidade IV, aborda-se transações e gatilhos.

\subsection{Instrumentos e procedimentos de coleta}

Como instrumentos de coleta de evidências, durante todo o estudo, foram adotadas as observações diretas, com a finalidade de identificar "comportamentos ou condições ambientais relevantes" para o estudo e determinar "a incidência de certos tipos de comportamentos durante certos períodos de tempo", conforme Yin (2015, pp. 115-116), e observações participantes, que possibilitam uma visão a

\footnotetext{
${ }^{3}$ Diferente dos softwares voltados para profissionais, o BR Modelo tem "foco no ensino e na aprendizagem da modelagem de dados relacional em nível técnico e acadêmico", conforme Candido and Santos Mello (2017, p. 96) [3]

${ }^{4}$ Disponível em: https://www.mysql.com/products/workbench/.
}

Figura 1: Hierarquia conceitual: Unidade I

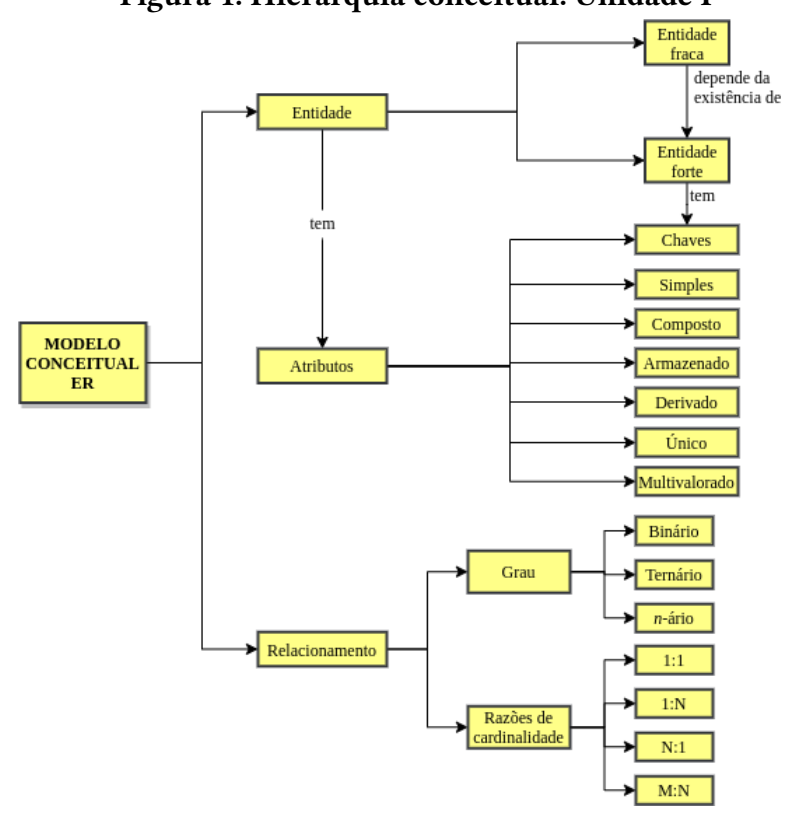

Figura 2: Hierarquia conceitual: Unidades II a IV

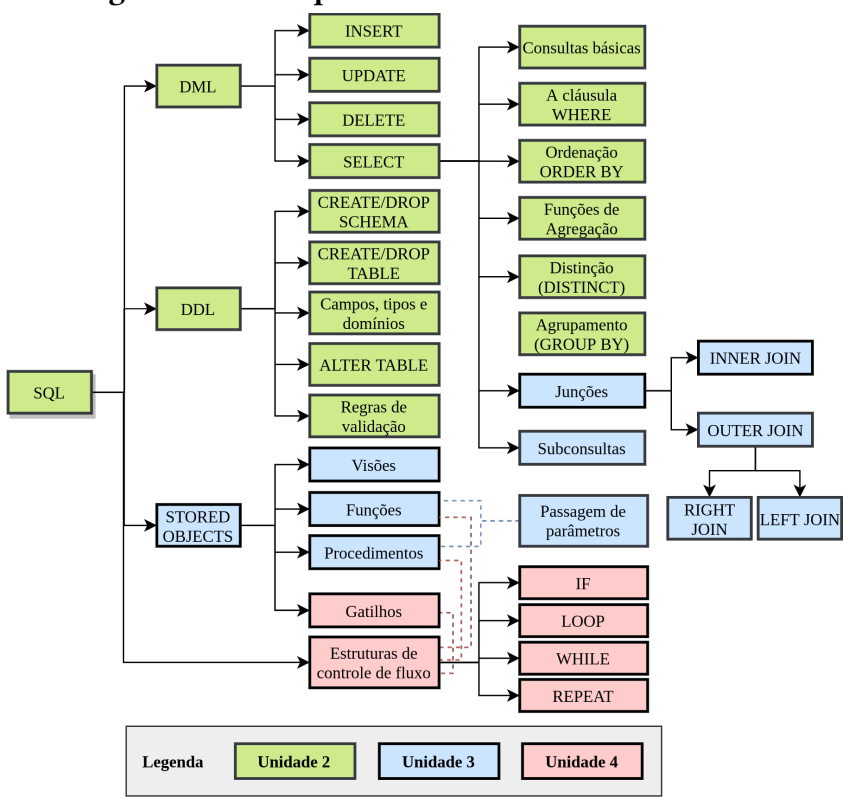

partir do "ponto de vista de alguém de "dentro" do estudo de caso, e não de um ponto de vista externo” [27].

Dos registros das observações, ao final da unidade I, elaboramos e aplicamos um questionário individual, via Google Forms, com cinco alternativas que mediram as respostas como positivas ou negativas às afirmações, inspiradas na escala Likert. As questões partiram da perspectiva dos "lugares comuns da educação" [22], 
originalmente propostos por Schwab (1973), que traz a compreensão de que, dada a complexidade de todo fenômeno educativo, a experiência educacional engloba quatro "lugares comuns" [13, 17]:

- o professor, responsável por elaborar as atividades e definir a sequência dos conhecimentos abarcados - ensino;

- o aprendiz, encarregado de optar pelo aprender, uma tarefa que não pode ser repartida;

- o currículo, que abarca "o conhecimento, as capacidades, e os valores da experiência educativa que satisfaçam critérios de excelência de tal modo que o convertam em algo digno de ser estudado", nas palavras de Novak e Gowin (1984, p. 22);

- o meio, o contexto em que se dá o fenômeno educativo, condiciona e interfere no significado do currículo para o professor e o aprendiz.

Segundo Moreira (1999), Novak propõe, ainda, um quinto elemento, correlacionado e codependente dos demais: a avaliação [13]

As questões, portanto, tiveram o intuito de coletar as percepções dos estudantes sobre o relacionamento com professor, materiais didáticos, avaliação, instituição e matriz curricular do curso, para compreender como ocorre o processo de aquisição/negociação de significados - partindo do pressuposto que a significação lógica e psicológica, bem como a disposição favorável são elementos essenciais para uma aprendizagem significativa.

Com base na forma de aquisição do conhecimento (por recepção/ por descoberta), sob os fundamentos da teoria de Ausubel, e a imitação como via para aprendizagem, trazendo uma perspectiva socio-interacionista, analisamos os tipos de aprendizagem predominantes na sala de aula no contexto estudado.

Ao final da unidade III, após a análise dos dados coletados nas observações e nos questionários, foram realizadas entrevistas semiestruturadas com $50 \%$ dos participantes (ou 13/26), cuja escolha ocorreu de maneira aleatória, de acordo com a disponibilidade e desejo/concordância dos estudantes em responder às questões. Os "informantes" - participantes que apresentaram olhares e interpretações a respeito das questões estudadas, além de indicar fontes para a investigação das evidências [27] -, nesta etapa, foram estudantes repetentes do $3^{\circ}$ ano.

Os participantes responderam 10 questões base, direcionadas a pontos considerados sensíveis, detectados nas etapas anteriores: o comportamento em relação à disciplina (se gostam da disciplina, se a consideram importante, interação e participação nas aulas, relação com outros conhecimentos adquiridos no curso, autoconfiança nas habilidades profissionais, etc.), relacionamento com o professor, bem como as estratégias de estudo e os métodos de avaliação.

(1) Quais são as diferenças que você nota em relação à disciplina no ano atual e no ano anterior que possam impactar na sua aprendizagem $?^{5}$

(2) Como você avalia sua participação/interação durante as aulas da disciplina no ano atual?

(3) De que forma você enxerga seu comportamento ou posicionamento a respeito da importância da disciplina na sua formação técnica?

(4) Em relação ao curso, você considera que a disciplina tem relevância? Se tivesse que avaliar com um número de 0 a 4 , qual seria sua avaliação?

\footnotetext{
${ }^{5}$ Essa questão foi feita apenas para estudantes que repetiram o $3^{\circ}$ ano.
}

(5) Você considera que as formas de avaliação adotadas pelo professor impactam no seu relacionamento com a disciplina? Você se sente seguro em relação às provas em laboratório?

(6) Os conhecimentos abordados na disciplina Banco de Dados se relacionam com outras disciplinas dentro da sua formação? Se sim, a quais conhecimentos você associaria?

(7) Que alternativas você mais utiliza para estudar para a disciplina: atendimentos, vídeos, ou livros técnicos? Você considera que os meios utilizados conseguem dar conta da sua aprendizagem?

(8) Na sua opinião, as atividades propostas na disciplina proporcionam a interação entre os colegas para a resolução de problemas ou exercícios? Se sim, de que forma isto acontece?

(9) Para além de questões técnicas, você considera possível associar os conteúdos da disciplina Banco de Dados com elementos "do mundo real"? Se sim, dê exemplos.

(10) No momento atual, se surgisse uma vaga de trabalho que requisitasse as competências relacionadas a modelagem de dados, você se sentiria tecnicamente preparado para assumila? Por quê?

Como traz Galeffi (2009, p. 53), é "na linguagem que se deve buscar o fio condutor de toda compreensão qualitativa criteriosamente construída" [9]. Por esta razão, intencionalmente, algumas questões da entrevistas foram semelhantes às perguntas dos questionários. O objetivo foi obter as respostas mais completas em relação aos dados coletados nos questionários iniciais, inclusive do ponto de vista pessoal/individual, já que os questionários foram aplicados ao final da unidade I e as entrevistas foram realizadas ao final da unidade III/início da unidade IV.

\section{AS LIÇÕES DA SALA DE AULA: RESULTADOS E DISCUSSÕES}

Nesta seção, apresentamos e discutimos dados coletados durante a pesquisa. As subseções que agrupam elementos da prática docente e das posturas dos estudantes enquanto sujeitos aprendentes. Destacamos, também, elementos que contribuíram ou dificultaram a aprendizagem sob a ótica dos estudantes.

\subsection{Descoberta, recepção e imitação}

A unidade I foi marcada pelo equilíbrio entre atividades que favoreceram uma aprendizagem por recepção - os conteúdos foram apresentados na sua forma final aos estudantes - e por descoberta exercícios de resolução de problemas.

Do ponto de vista da organização do ensino, as aulas expositivas serviram para preparar os estudantes para a abordagem baseada em exercícios de resolução de problemas ou estudos de caso referentes ao modelo ER, contribuindo para pavimentar o caminho para a etapa posterior, com introdução da SQL, com o uso de organizadores prévios comparativos baseados em tópicos da $\mathrm{POO}$ (programação orientada a objetos) como classes, objetos, atributos e herança.

Essa estratégia de combinar aulas expositivas com atividades baseadas em problemas foi importante porque, como aponta $\mathrm{Au}$ subel, no contexto de disciplinas acadêmicas, são poucos os casos em que atividades baseadas em resolução de problemas - essência da aprendizagem por descoberta - são efetivamente bons meios 
primários de transmissão do conteúdo, visto que, de acordo com $\mathrm{Au}$ subel (2000, p. 46), proposições assim aprendidas dificilmente "são suficientemente originais, significativas ou valem a pena incorporar ao conhecimento do assunto do aluno" [2].

Com base nas respostas dos estudantes, observamos que os exercícios baseados em resolução de problemas tiveram importância para a assimilação dos conceitos tanto em tempo de aula, quanto nos atendimentos. Quando questionado a respeito das estratégias de estudo, o estudante $\mathrm{A}$, que repete o $3^{\circ}$ ano após reprovação na disciplina Banco de Dados, destacou a importância do tempo destinado pelo professor à prática em sala nas aulas e nos atendimentos.

Além disso, as interações entre os pares para a resolução das atividades contribuiu para a negociação de significados e uma disposição favorável. A busca por soluções ante aos erros por meio de discussões com colegas e professores regente e em formação, foi uma via essencial para uma aprendizagem durante o ano letivo:

(ESTUDANTE A) (...) quando eu vou fazer uma coisa e eu erro nela, eu bato cabeça para aprender, então eu busco em seja qual for a fonte: internet, professor.. livro, raramente, porque eu não consigo achar tão diretamente o que eu quero, entendeu? Eu descubro qual é o motivo do meu erro e não repito mais. Só que, você sempre vê, eu tava aqui sempre em atendimento, então, por mais que eu tivesse passado na matéria, eu vinha aqui em atendimento porque uma dúvida que ele tirasse de alguém poderia me favorecer.

Durante as observações, sobretudo nos atendimentos, o processo de resolução dos exercícios demonstrou a moldagem dos materiais aos quais os estudantes foram expostos - a produção de uma forma individual, indispensável a uma aprendizagem significativa, pois corresponde à incorporação de maneira subjetiva e específica em cada estudante de tais conteúdos. Os indícios foram evidenciados nos momentos de interação, em que os estudantes que apresentaram maiores avanços na resolução das atividades explicaram e justificaram aos pares as soluções adotadas.

Com os exercícios, o material não foi exposto na íntegra aos estudantes. Deste modo, ainda que por tentativa e erro, pesquisas e testes de soluções outrora implementadas, encontradas em fóruns e sites da internet, o conteúdo foi descoberto, num contexto em que a interação foi essencial por propiciar as trocas entre o professor regente, os estudantes mais experientes e os demais colegas.

Para o estudante $\mathrm{A}$, as aulas inteiramente dedicadas à resolução de exercícios baseados em cenários reais são um contraponto ao que ocorre em outras disciplinas específicas do curso, que focam em aulas expositivas. No comentário abaixo, o estudante destaca as tarefas de resolução de problemas em sala de aula com mediação docente e o contraste com outras disciplinas específicas do curso de Informática no tocante aos métodos de ensino:

(ESTUDANTE A) Tem matérias que o professor só ensina, ensina, ensina, e depois cobra. Os alunos, a gente tem uma vida fora, a gente não sabe o que cada um passa em casa, não sabe o que cada um tem necessidade. Não pode achar que eles [os colegas] estão sempre praticando em casa, as coisas nem sempre são assim... então, você dar um momento de aula para praticar é sempre a melhor coisa, porque, principalmente o professor, desde o ano passado, dá aula de um assunto e tira uma outra [aula] para a gente praticar... aí ele vai olhando, a gente vai lá tirar dúvidas com ele nos atendimentos, que ele chama a gente pra vir nos atendimentos dele e obriga a gente a praticar, praticar, praticar, até que não tenha mais dúvidas.

Assim como numa perspectiva sociointeracionista Vygotsky traz a imitação como via para o aprendizado, não apenas de forma mecânica de reprodução vazia, mas como ocasião favorável para a re-elaboração interna dos conhecimentos captados externamente [19], tivemos momentos que privilegiaram a imitação durante a apresentação dos conteúdos no ensino de discente para discente - superando a lógica de ensino por transmissão de docente para discente.

Percebemos que as experiências na vida escolar pregressa tiveram impacto na visão dos estudantes sobre a instituição de ensino, o curso e o professor. O discurso predominante denota pouca disposição e autonomia para as disciplinas específicas do curso de Informática - incluindo Banco de Dados -, o que também é reflexo de um estigma do curso e da instituição, expresso na ideia de que Informática é difícil e/ou de que o instituto tem uma cobrança exacerbada sobre os estudantes.

A estudante $\mathrm{B}$, assim como o estudante $\mathrm{A}$, também repetindo o $3^{\circ}$ ano em razão da disciplina Banco de Dados, faz uma autoavaliação sobre o comportamento em relação à disciplina no ano anterior, em que afirma que apresentou muitas dificuldades, precisando, inclusive, de orientação e acompanhamento psicológico.

(ESTUDANTE B) Rapaz, assim: ano passado eu tive muita dificuldade com Banco de Dados, então esse ano eu procurei ser maior que os problemas que eu enfrentei ano passado com a matéria. Eu tive acompanhamento com a psicóloga, conversei bastante com ela, tipo... Ela me auxiliou de que forma eu deveria me comportar e tal, para conseguir não ter tantas dificuldades esse ano na matéria e, eu não tive, de fato.

A mesma estudante, no comentário abaixo, reforça a aprendizagem por recepção como fenômeno no ensino da disciplina, sobretudo a partir da unidade II, em que as estratégias de ensino privilegiaram a apresentação do conteúdo, embora isto tenha ocorrido em alternância com atividades baseadas na resolução de problemas.

Como expressão da heterogeneidade da turma, corroborando a perspectiva de que os conhecimentos encaixam-se de forma particular na estrutura cognitiva de cada estudante, o avanço no decorrer da disciplina ocorreu de formas diferentes. A contribuição dessa heterogeneidade foi significativamente perceptível, sobretudo, durante os momentos de resolução coletiva de problemas nos atendimentos, de modo que puderam ajudar dos demais colegas ao compartilhar descobertas de conteúdos/conhecimentos referentes aos tópicos abordados. Soma-se a isso, ainda, os exemplos ilustrados pelos diagramas ER, scripts SQL e vídeos das aulas, divulgados no blog do professor regente.

(ESTUDANTE B) Eu mudei mais meu comportamento na questão do sentar na frente, porque eu tenho problema de vista e, tipo, às vezes eu sentava no fundo $\mathrm{e}$ terminava não enxergando o que tava acontecendo, 
o que ele [o professor] estava fazendo no quadro e ficava por aquilo mesmo. Achava que depois eu ia conseguir pegar, que depois eu ia conseguir entender, e eu não conseguia. Esse ano eu comecei a sentar na frente; tudo que ele fazia no quadro, eu ia e fazia no computador, e deu para ver a diferença nas notas, né?!

O caso da estudante B, conforme o comentário acima, expressa bem essa relação com a disciplina, a imitação e a aprendizagem por recepção. No ano anterior, a estudante foi prejudicada em razão de um problema de visão. Neste sentido, de modo geral, identificamos que a imitação/recepção fez-se presente no processo de aprendizagem dos estudantes, tanto no que se refere à prática docente - o professor privilegia aulas expositivas - quanto ao comportamento dos estudantes - a expectativa pela exposição do conteúdo e imitação.

No início da unidade II, seguindo a hierarquia conceitual dos tópicos da disciplina, o tópico de consultas básicas foi introduzido por meio de aulas expositivas, expressando, mais uma vez, o predomínio de uma aprendizagem por recepção. A introdução de tópicos como distinção (SELECT DISTINCT), ordenação (ORDER BY), agrupamento (GROUP BY) e funções de agregação, por sua vez, aconteceu por métodos que mesclaram a demonstração de tais recursos, seguido de exercícios baseados em pequenos problemas.

Questionamos de que maneira a hierarquia conceitual e a organização curricular influem na elaboração de estratégias de aprendizagem (questão de pesquisa 1). Após as interpretação dos dados, concluímos que a hierarquia conceitual privilegiou a aquisição dos conceitos e proposições da SQL enquanto a abordagem da modelagem de dados, reduzida à unidade I, refletiu no esquecimento dos conceitos abordados no início do ano letivo.

A organização do ensino privilegiou aulas expositivas. A partir das entrevistas, dos questionários e das observações, concluímos que os conhecimentos prévios de outras disciplinas tido pouco reflexo no processo de assimilação na disciplina Banco de Dados sobretudo, a questão 6 da entrevista demonstra esse processo, visto que, com raras exceções, poucos conseguiram apresentar referências às outras disciplinas. Quando a referência ocorreu, foi sempre relacionada à disciplina Linguagem Técnica I (LT I).

\subsection{Materiais potencialmente significativos}

Mesmo em casos em que os temas foram explicitamente comparados, inclusive, com o uso de organizadores prévios baseados em outras disciplinas, houve bastante dificuldade dos estudantes em relacionar os conhecimentos dessas outras disciplinas com os assuntos abordados na disciplina Banco de Dados.

Foram considerados como materiais potencialmente significativos - com a possibilidade de tornar-se âncoras para uma aprendizagem significativa como conhecimentos já existentes na estrutura cognitiva dos estudantes -, os seguintes conteúdos essenciais na base tecnológica das disciplinas da área técnica previstas no plano de curso (IFBA, 2010):

- Algoritmos ( $2^{\circ}$ ano, carga horária: $\left.120 \mathrm{~h}\right)$ :

(1) Variáveis, constantes, tipos, identificadores, palavras reservadas;

(2) Estruturas de repetição;

(3) Estruturas de controle;
(4) Variáveis Heterogêneas: registros e tipos definidos;

(5) Subprogramas: procedimentos e funções, passagem de parâmetros (métodos);

(6) Arquivos: texto e dados; busca, alteração, exclusão e inserção em arquivos de dados; aplicação em programas.

- Linguagem Técnica I (LT I, $3^{\circ}$ ano, 60h):

(1) Classes, objetos, atributos;

(2) Orientação a objetos (conceitos avançados): Herança

Partindo do ponto de vista lógico, potencialmente significativo, considerando que, de acordo com Teorey et al. (2013, p. 15), as entidades reúnem os "dados sobre os quais informações devem ser coletadas" [25], foi possível para os estudantes, associar com o conceitos de classe - embora esta tarefa não tenha ocorrido de forma trivial. Da mesma maneira, uma "ocorrência específica de uma entidade é chamada de instância da entidade”, relacionado ao conceito de objeto da POO.

Como os relacionamentos correspondem à relação entre entidades e "não possuem existência física ou conceitual além de sua dependência das entidades associadas", no processo de "tradução" do modelo ER para SQL, assim como as entidades, são relacionados às tabelas - material ligado à própria disciplina.

Os atributos, enquanto descritores ou identificadores de entidades e relacionamentos, foram associados às colunas das tabelas SQL. Já o valor do atributo, uma "ocorrência em particular de um atributo", são relacionados às linhas da SQL e aos valores dos atributos (propriamente ditos) de um objeto na abordagem de POO.

Essa relação de conteúdos de outras disciplinas com materiais de Banco de Dados ficou mais forte ao final da unidade I e início da unidade II, ao passo que os estudantes conseguiram, com os estudos de SQL, trazer essas relações de maneira mais notável.

\subsection{Interação como fator de aprendizagem}

Impulsionados pela pouca disponibilidade de livros didáticos específicos para educação profissional, o professor regente disponibilizou videoaulas, na plataforma YouTube, que reforçaram a disposição dos estudantes com a disciplina, enquanto estratégia de estudo adotada em outras disciplinas.

Com a maioria dos vídeos capturados diretamente das aulas, este recurso passou a fazer parte das estratégias de aprendizagem, importantes para recuperação das informações adquiridas. Sob o ponto de vista da teoria sociointeracionista de Vygotsky, segundo Rego (2013, p. 109) "as funções psíquicas humanas estão intimamente vinculadas ao aprendizado, à apropriação (por intermédio da linguagem) do legado cultural de seu grupo" [19].

Nesse sentido, observamos nas aulas, nos questionários e nas entrevistas, como recurso para revisão dos conteúdos, os vídeos foram importantes para a apropriação dos conceitos abordados na disciplina, ao possibilitar a imitação de comandos, tornando propícia uma aprendizagem individualizada e, sobretudo, ampliar a compreensão e a relação dos novos conteúdos com os conhecimentos prévios [18] - atuando como recurso importante no processo de negociação de significados.

Os discentes deixaram de usar os livros disponíveis na biblioteca como parte das estratégias de estudo, principalmente após a unidade I. Sobre isso, alguns participantes comentaram que não utilizam os livros também em outras disciplinas em razão das próprias 
estratégias de estudo, enquanto outros criticaram os conteúdos dos livros disponíveis no acervo da instituição.

Para o estudante $\mathrm{C}$, isso aconteceu porque há livros que trazem uma riqueza de detalhes ora exagerada, ora diminuta, tornandoos pouco proveitosos para buscas imediatas durante os estudos: "às vezes tem muito detalhe, às vezes falta alguma coisa que a gente precisa entender porque que tá ali e não tem uma explicação mais concreta"; para ele, nestes casos, participar dos atendimentos e assistir às videoaulas consistem em experiências mais enriquecedoras.

Como aliadas nas estratégias de aprendizagem, as videoaulas em conjunto com os exercícios baseados em cenários descritos no formato de problemas, contribuíram para a significação psicológica e da disposição favorável enquanto requisitos para uma aprendizagem significativa. Na entrevista, registrou-se a noção dos exercícios como parte essencial para o estudo.

(ESTUDANTE D) Eu acho que ajuda, porque tem coisas que eu acabo não pegando durante a aula, porque às vezes eu me distraio, e tal... E aí, com as [gravações das] aulas, eu consigo render e aí eu consigo pegar o que eu não consegui ter pegado no momento (da aula), entendeu? E você vendo mais de uma vez como é que faz cada coisa, como é que é o comando e tal... Você consegue lembrar mais facilmente do que você só ver uma vez na aula, mais rapidamente e tal.

Assim, como complemento, os vídeos ajudaram a compreender os assuntos tratados no período, já que, conforme demonstraram as respostas nos questionários (figura 4): $27 \%$ (ou 8/26) dos estudantes concordaram que sentem falta de um material didático voltado para a disciplina (Q20); por outro lado, 34,6\% (ou 9/26) discordaram; outros $34,6 \%$ (ou 9/26) mantiveram neutralidade.

5.3.1 Sobre a interação com o professor. Questionamos os estudantes sobre os métodos de ensino, 92,3\% (ou 24/26) concordaram totalmente que analisar coletivamente com o professor e a turma as questões dos exercícios e avaliações ajuda a melhorar a compreensão do assunto (Q3), 7,7\% (ou 2/26) ficaram neutros; além disso, 46\% (ou $12 / 26$ ) concordaram que se sentem estimulados(as) pelo docente a participar da aula por meio questionamentos ou comentários ligados aos temas tratados (Q4), ao passo que 39\% (ou 10/26) mantiveram neutralidade e $15 \%$ (4/26) discordaram, conforme dados ilustrados na figura 3.

No tocante à disponibilidade do professor, $85 \%$ (ou 22/26) dos discentes discordam que o professor não se mostra disponível fora de sala de aula, em atendimentos ou virtualmente por e-mail e comunicação instantânea (Q6), enquanto outros 15\% (ou 4/26) permanceram neutros. Na questão (Q5), 88\% (ou 23/26) discordaram sobre a forma que o conteúdo é apresentado em sala de aula ser ruim e $12 \%$ (ou 3/26) ficaram neutros. Em complemento, $77 \%$ (ou 20/26) discordaram, 19\% (ou 5/26) adotaram posição de neutralidade e $4 \%$ $(1 / 26)$ sobre as aulas serem ruins (Q1).

5.3.2 Sobre a disciplina, avaliação e autoavaliação. Nos questionários, nas respostas referentes à autoavaliação, $42 \%$ (ou 11/26) dos estudantes concordam que frequentar os atendimentos contribui para o aprendizado da disciplina (Q21), 35\% (ou 9/26) ficaram neutros e $23 \%$ (ou 6/26) discordaram.
Figura 3: Respostas dos estudantes sobre a relação com o professor regente da disciplina Banco de Dados

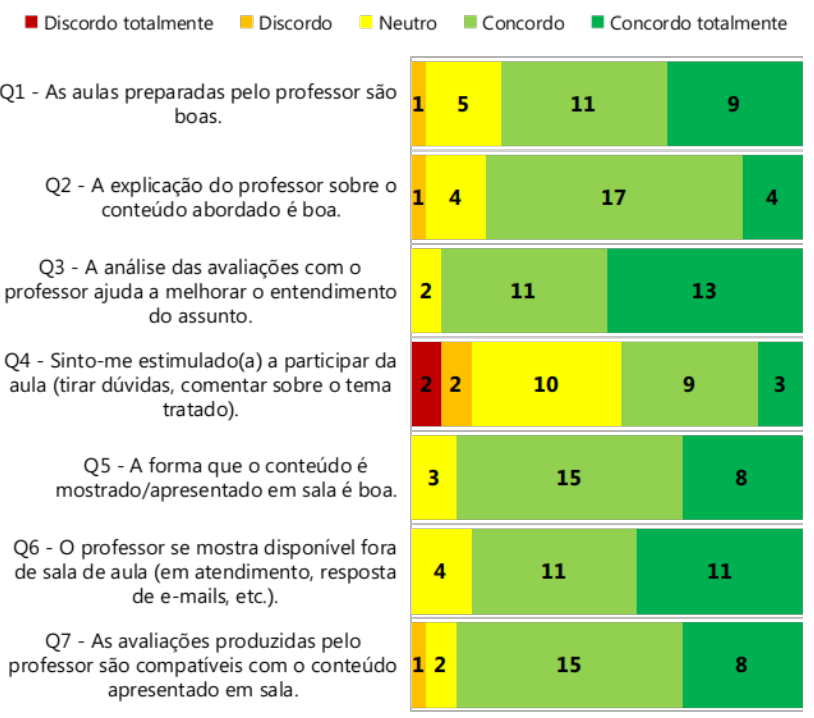

Como ilustra a figura 4, na primeira etapa da pesquisa, constatamos que $58 \%$ (ou 15/26) ficaram neutros sobre a afirmativa de que $a$ disciplina tinha um alto grau de dificuldade (Q19), enquanto $31 \%$ (ou 8/26) concordaram e $11 \%$ (ou 3/26) discordaram. Sobre importância da disciplina (Q18), 58\% (ou 15/26) concordaram que a disciplina é importante dentro da formação, $4 \%$ (ou 1/26) discordaram e $38 \%$ (ou 10/26) adotaram a neutralidade.

Durante as observações e nas entrevistas percebemos que os estudantes reproduzem um discurso de punição sobre as avaliações. Embora as respostas tenham sido mistas, predominou a oposição às provas/exames em laboratório; nas entrevistas, houve reclamação sobre o peso na nota e o tempo encurtado da prova (80 minutos) em relação às aulas (100 minutos), sob a alegação de que "causa estresse". Por outro lado, os estudantes reconheceram que as avaliações são compatíveis com o conteúdo apresentado em sala (Q7, figura 3) $88,5 \%$ (ou $23 / 26$ ) concordaram, $7,7 \%$ (ou $2 / 26$ ) ficaram neuros e $3,8 \%$ (1/26) discordaram.

Ao comparar a própria compreensão sobre as avaliações no ano interior e no ano atual na disciplina, a estudante B traz as provas/exames realizadas no laboratório de informática como momentos de tensão e necessidade de cuidado no gerenciamento de emoções. Como apresentamos na subseção 5.1, a estudante relata que precisou de acompanhamento psicológico.

(ESTUDANTE B) A diferença [desse ano] para o ano passado foi gritante, mas eu continuo, sabe? [respira fundo] Quando eu vou fazer prova de Banco, primeiro eu sento, eu respiro, eu digo "calma, você consegue" [...] e depois eu vou e faço a prova porque tipo... eu sei, então, não vou ficar nervosa por que [enfatiza] eu sei fazer e eu vou conseguir fazer, aí eu vou, me controlo, fico na minha e faço. 
Figura 4: Respostas sobre a disciplina e autoavaliação dos estudantes no questionário

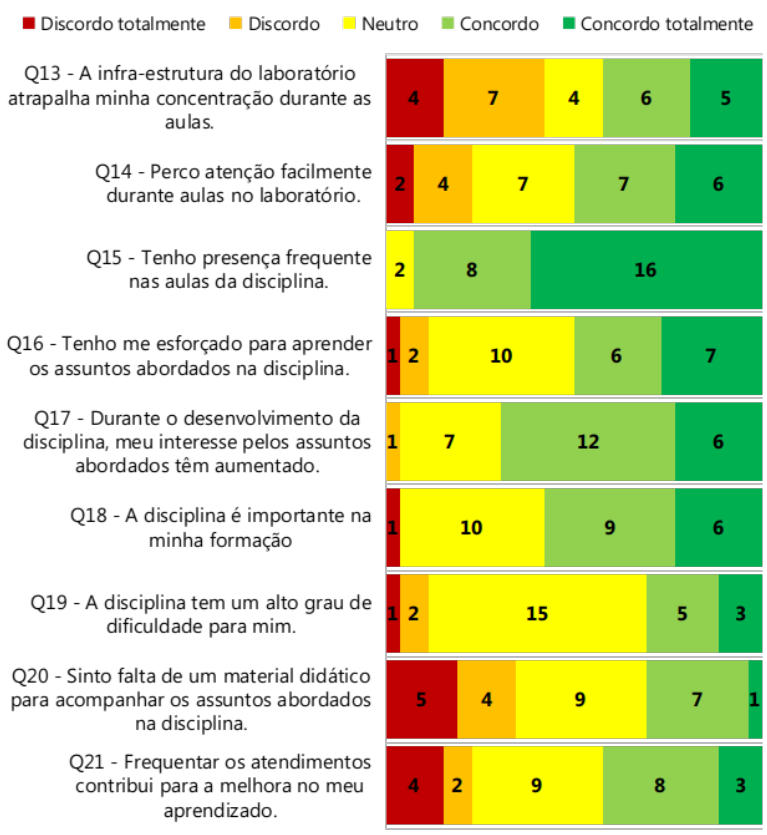

Outro aspecto que notamos é a dinâmica do laboratório de informática, onde os estudantes tendem a perder facilmente a atenção, com distrações dos computadores, burburinhos de conversas paralelas e celulares. Nas respostas ao questionário (Q14), 50\% (ou 13/26) concordaram que é fácil desfocar-se nas aulas em laboratório, ao passo $23 \%$ (ou 6/26) discordaram, e outros $27 \%$ (ou $7 / 26$ ) ficaram indecisos. Percebemos que a estrutura não ajuda: às vezes, faltam máquinas para alguns estudantes, o que gera a necessidade de que, ou eles levem seus próprios computadores, ou sentem-se em duplas.

Todos esses elementos ajudam a compreender de que maneira a relação dos estudantes com as instituições, o curso, o grupo onde estão inseridos e o professor regente influem na aprendizagem, como levantado na questão de pesquisa 2. Ao favorecer a troca entre os participantes, nos atendimentos buscou-se privilegiar uma aprendizagem, sobretudo, por descoberta - mas sem descartar o potencial da interação entre estudantes, por uma aprendizagem por recepção.

Por outro lado, a relação com o curso foi problemática em alguns casos. No $3^{\circ}$ ano, penúltima série do ensino médio integrado, de acordo com a matriz curricular praticada, muitos estudantes ressaltam a busca por um ensino médio de qualidade, socialmente referenciado, mas demonstram não ter criado uma visão positiva em relação à formação técnica.

A partir das respostas nas entrevistas e nos comentários no cotidiano das aulas, entendemos que este é um obstáculo a uma aprendizagem significativa, visto que conceitos, ideias e proposições tendem, nestes casos, a ser aprendidos mecanicamente, com o intuito de obter aprovação no ano letivo.

\subsection{Outros aspectos relacionados}

Tivemos relatos de dificuldades no gerenciamento do tempo disponível para atividades extra-classe, seja em casa ou na própria instituição, relato comum pela idade e locais de origem dos estudantes. Além disso, aspectos econômicos influenciaram na prática; além de alguns estudantes não poderem permanecer na instituição no turno oposto - quando ocorrem os atendimentos -, alguns relatos recaem na ausência de um computador equipado.

No contexto da metodologia de ensino adotada na disciplina, para a prática de exercícios fora dos laboratórios de Informática da instituição, seria preciso, no mínimo, um computador equipado com uma ferramenta CASE (Computer-Aided Software Engineering), adequada para as atividades. O comentário do estudante $\mathrm{C}$ no questionário expressa esses pontos: só consigo praticar no colégio por conta de problemas com meu equipamento, e isso dificulta o processo.

O domínio de ferramentas CASE também faz parte dos conteúdos tecnológicos essenciais. Durante a unidade I, notamos que a maioria os estudantes preferiam resolver os problemas sempre utilizando o Workbench, em vez de utilizar o papel. Quando questionados, $77 \%$ (ou 20/26) dos estudantes concordaram que preferem utilizar o Workbench para resolver os exercícios de modelagem no computador (Q12), enquanto 8\% (ou 2/26) discordaram e 15\% (ou 4/26) adotaram posição de neutralidade; $61,5 \%$ (ou 16/26) concordaram que é fácil usar o Workbench para resolver as questões (Q11), ao passo que $15,4 \%$ (ou $4 / 26$ ) discordaram e $23,1 \%$ (ou 6/26) ficaram neutros.

Outro comentário que ilustra a questão da falta de recursos (e da importância da assistência estudantil) como obstáculo de aprendizagem é o da estudante $\mathrm{E}$, que, como a maior parte da turma, mora em outro município.

(ESTUDANTE E) Agora tá bem complicado pra estudar, eu tô ficando aqui de tarde para estudar porque meu notebook queimou a tela. Eu vim outro dia pro atendimento porque eu já tava aqui à tarde. $\mathrm{O}$ auxílio [do Programa de Assistência Estudantil] começou a sair tem pouco tempo e, antes disso, condições de ficar aqui à tarde tavam bem complicadas... Aí na semana que eu comecei a poder ficar, não tinha transporte. (...) Só a passagem. Aí tava complicado ficar aqui pros atendimentos, principalmente na segunda unidade... eu tomei bomba na nota... foi essa unidade que me quebrou em Banco de Dados, né? E, principalmente nessa unidade, que foram os assuntos que eu não tava entendendo e não tinha auxílio... Conseguir dinheiro para ficar aqui era complicado... O professor me chamou várias vezes pra eu vir pro atendimento, mas eu não conseguia ficar aqui.

Constantemente, os estudantes são afetados por problemas como a ausência de transporte escolar regular. No relato, a estudante afirma que teve um período de dificuldade para participar de atividades no turno oposto - o que inclui os atendimentos de várias disciplinas além de Banco de Dados.

\subsection{Ameaças, limitações e confiabilidade}

Yin recomenda, para avaliar a validade externa de um estudo de caso, reproduzir as "descobertas em um segundo ou mesmo em um terceiro local, nos quais a teoria supõe que deveriam ocorrer os 
mesmos resultados", com o intuito de verificar a teoria [27]. Esta é uma das limitações deste estudo: em razão do custo considerável de realizá-lo em outras instituições, não foi possível generalizá-lo sendo realizado em apenas uma instituição. Todavia, este estudo ainda assim permite vislumbrar a realidade de estudantes em outros contextos e, enquanto pesquisa qualitativa, como aponta Creswell (2010, p. 228), é relevante "na descrição específica e nos temas desenvolvidos no contexto" em que a pesquisa foi realizada [8].

Entre as estratégias de validade, a triangulação de fontes possibilitou observar a convergência dos dados, expressos nos fenômenos observados e anotados, e a perspectiva dos participantes, como recomenda Creswell. Pelas observações diretas e participantes, registramos em diário as estratégias de ensino do professor (formato das aulas, tipo de exercícios adotados, atitudes durante a execução das atividades), a descrição da interação entre professor regente e estudantes e as atitudes de discentes (participação nas aulas, interesse e opinião acerca do curso e da disciplina, motivações pessoais).

Nos questionários, as perguntas seguiram essa mesma forma com a limitações das questões fechadas. Essa limitação foi solucionada nas entrevistas, realizadas antes ou após o tempo de atendimento, em salas isoladas. As questões elaboradas foram submetidas à avaliação pelo professor regente, pelos informantes e, após os refinamentos, apresentadas aos demais participantes entrevistados. Os registros em áudio foram autorizados pelos participantes e as entrevistas foram transcritas mantendo as identidades ocultas.

No entanto, uma ameaça à validade das entrevistas, reside nas "imprecisões devido à memória fraca do entrevistado" [27] - quando, no momento da entrevista, os participantes hesitaram ou tiveram dificuldade de lembrar-se de algo que fora questionado. Para atenuála, tanto em relação aos questionários - que os estudantes puderam escolhar onde e quando, dentro do prazo estipulado, responderiam às questões: no celular, no laboratório de informática ou mesmo em casa - quanto em relação às entrevistas, que ocorreram no tempo ocioso dos estudantes na instituição.

\section{CONSIDERAÇÕES FINAIS}

Neste trabalho, trouxemos uma análise panorâmica sobre aprendizagem de modelagem e tecnologia de banco de dados, partindo de elementos comuns aos fenômenos educativos. Ressaltamos que a proposta da pesquisa aqui apresentada não foi avaliar se houve ou não aprendizagem significativa da parte dos estudantes no contexto abordado - sobretudo, em razão da dificuldade de mensurar se um conhecimento foi aprendido de forma significativa de fato. Assim, a contribuição, porém, revela-se na compreensão dos fenômenos educacionais abordados ao longo do texto.

Reforçamos que aprendizagem significativa só é possível se o aprendiz deseja aprender significativamente - e não apenas para passar de ano - apresentada por Ausubel e seus interlocutores. $\mathrm{O}$ currículo, os métodos de ensino, tendências pedagógicas e as próprias motivações e necessidades do estudante, neste contexto, influem direta ou indiretamente na aprendizagem.

Concluímos que os conceitos foram melhor assimilados pelos estudantes pelo significado prático que traziam em si, trazendo elementos para uma aprendizagem potencialmente significativa, visto que os discentes contaram com conhecimentos prévios que puderam relacionar com os novos materiais de aprendizagem. Ainda assim, poucos estudantes puderam relacionar os conceitos de outras disciplinas (aqui, mencionamos Algoritmos e LT, as mais citadas entre os discentes) com conceitos de banco de dados. Para resolver esta dificuldade, especialmente na etapa da modelagem conceitual ER - o uso de organizadores prévios seria uma solução possível.

Observamos que a escassez de livros didáticos direcionados para o curso técnico integrado - fugindo de uma postura meramente tecnicista, com ênfase nos manuais - é um ponto sensível, que carece de investigação e produção de novos materiais, já que existem livros didáticos também para outras disciplinas. Por outro lado, há soluções alternativas, como a adotada na disciplina, com gravação de videoaulas e disponibilização em plataforma online. A relevância dos vídeos deu-se em relação à complementaridade às atividades desenvolvidas em sala e consonância com a organização e o planejamento didático.

O interesse pelo curso e a relação com a turma e o professor influenciaram na aprendizagem, evidenciando a relação entre os elementos que compõe os processos de construção e negociação de significados. Alguns participantes apontaram que buscaram a instituição, principalmente, em razão da qualidade de ensino; outros, por outro lado, mesmo tendo esse foco inicialmente, desenvolveram interesse pela formação profissional - o que pode contribuir para uma aprendizagem significativa.

De modo geral, concluímos que o predomínio de avaliações somativas do tipo prova/exame criou uma perspectiva de punição, que gerou situações como as expostas aqui, mas que podem não estar restritas à disciplina Banco de Dados. Soma-se a isso o estigma sobre a dificuldade no curso de Informática que, muitas vezes, somado à ideia de que o ensino no instituto exige demais dos estudantes, que prejudicou a motivação dos discentes para aprender. Mesmo com um esforço com materiais potencialmente significativos, alguns estudantes optaram por ater-se à aprovação, o que tende a gerar uma aprendizagem mecânica em razão de uma resistência ao aprendizado de maneira significativa na disciplina.

O esquecimento recorrente dos conceitos relacionados à modelagem conceitual, concentrados na unidade I, como ilustra a figura 1, com o decorrer do ano letivo é um dos desafios da prática. Uma alternativa ao formato atual seria organizar o ensino a partir da generalidade dos conceitos relacionados aos conteúdos da base tecnológica, partindo dos mais inclusivos e concretos, passíveis de demonstração empírica, em direção a conceitos mais específicos, evidenciando as relações que envolvem tais conceitos entre si [21].

Além disso, são necessários metodologias de ensino e recursos pedagógicos que possibilitem abordagens diferenciadas e a superação da desarticulação entre os componentes curriculares, que, dificulta a concepção de relações entre conteúdos de disciplinas diversas e, assim, atuar como obstáculo a uma aprendizagem significativa. Um caminho possível para isto seriam os projetos integradores - que aparecem no currículo de referência para a educação profissional da CIEB (2020) - ao longo do processo formativo e não apenas como trabalho de conclusão de curso (TCC), como ocorre atualmente.

Para além da tecnologia de banco de dados, os caminhos em direção a uma aprendizagem significativa em Informática são longos e complexos, mas a mudança é possível e necessária. Para isto, é preciso observar as peculiaridades de docentes e estudantes, do contexto e dos conhecimentos e das avaliações no âmbito da educação profissional em Informática. 


\section{REFERÊNCIAS}

[1] Gilberto Astolfi and Dejahyr Lopes Junior. 2016. Ensino de Linguagem de Programação com Ênfase na Aprendizagem Significativa. In Anais do XXIV Workshop sobre Educação em Computação (Porto Alegre). SBC, Porto Alegre, RS, Brasil, 111-120. https://doi.org/10.5753/wei.2016.9654

[2] David Paul Ausubel. 2000. The acquisition and retention of knowledge: A cognitive view. Springer Science \& Business Media.

[3] Carlos Henrique Candido and Ronaldo dos Santos Mello. 2017. Ferramenta de Modelagem de Banco de Dados Relacionais brModelo v3. In Anais da XII Escola Regional de Banco de Dados (Passo Fundo). SBC, Porto Alegre, RS, Brasil. https://sol.sbc.org.br/index.php/erbd/article/view/3032

[4] Ronney Moreira de Castro and Sean Wolfgand Matsui Siqueira. 2018. Desenvolvimento e Avaliação de uma Metodologia de Aprendizagem Ativa Apoiada pelo uso de QR Code para Ensino de Banco de Dados. In Anais do XXVI Workshop sobre Educação em Computação (Natal). SBC, Porto Alegre, RS, Brasil. https://doi.org/10.5753/wei.2018.3526

[5] CIEB. 2020. Currículo de Referência para o Curso Educação Profissional Técnica de Nível Médio em Tecnologia e Computação. CIEB, São Paulo.

[6] Marcos Corino, Silvia Bertagnolli, and Marcelo Schmitt. 2020. Desenvolvimento e Aplicação de uma Estratégia Pedagógica para o Ensino de Redes de Computadores com Robótica Educacional. In Anais do XXXI Simpósio Brasileiro de Informática na Educação (Online). SBC, Porto Alegre, RS, Brasil, 1663-1672. https://doi.org/ 10.5753/cbie.sbie.2020.1663

[7] Monaly Correia, Breno Sousa, Raí Ferreira, and Patrick Brito. 2019. TreineBD: uma ferramenta de aprendizagem de banco de dados. In Anais da XIX Escola Regional de Computação Bahia, Alagoas e Sergipe (Ilhéus). SBC, Porto Alegre, RS Brasil, 449-456. https://sol.sbc.org.br/index.php/erbase/article/view/9007

[8] John W Creswell. 2010. Projeto de pesquisa: métodos qualitativo, quantitativo e misto. Artmed, Porto Alegre.

[9] Dante Augusto Galeffi. 2009. O rigor nas pesquisas qualitativas: uma abordagem fenomenológica em chave transdisciplinar. In Um rigor outro sobre a qualidade na pesquisa qualitativa: educação e ciências humanas, Roberto Sidnei Macedo, Dante Galeffi, and Âlamo Pimentel (Eds.). EDUFBA, Chapter 1, 13-74.

[10] João Marcelo Borovina Josko. 2020. A Problem-based Approach to teach Physical Database Design: an experience report. In Anais do XXVIII Workshop sobre Educação em Computação (Cuiabá). SBC, Porto Alegre, RS, Brasil, 11-15. https://doi.org/10.5753/wei.2020.11120

[11] Elena Martín and Isabel Solé. 2004. A aprendizagem significativa e a teoria da assimilação. In Desenvolvimento psicológico e educação: Psicologia da educação escolar, Â.; Palácios J. Coll, C.; Marchesi (Ed.). Vol. 2. Artmed, Porto Alegre, 61-81.

[12] Adriana Martinhago, Rodrigo Smarzaro, Iasmini Lima, and Leidiane Guimarães. 2014. Computação Desplugada no Ensino de Bancos de Dados na Educação Superior. In Anais do XXXII Workshop sobre Educação em Computação (Bras Ãlia). SBC, Porto Alegre, RS, Brasil, 21-29. https://sol.sbc.org.br/index.php/wei/article/ view/10956

[13] Marco Antonio Moreira. 1999. Teorias de Aprendizagem. EPU, São Paulo.

[14] Marco Antonio Moreira. 2011. O que é afinal aprendizagem significativa? In Aprendizagem significativa: a teoria e textos complementares, Marco Antonio Moreira (Ed.). Editora Livraria da Física, São Paulo.

[15] Joseph D Novak. 2002. Meaningful learning: The essential factor for concep tual change in limited or inappropriate propositional hierarchies leading to empowerment of learners. Science education 86, 4 (2002), 548-571. https //onlinelibrary.wiley.com/doi/pdf/10.1002/sce.10032

[16] Joseph D Novak and Alberto J Cañas. 2006. The theory underlying concept maps and how to construct them. Florida Institute for Human and Machine Cognition 1 1 (2006), 1-31.

[17] Joseph D Novak and D Bob Gowin. 1984. Aprender a Aprender (1th ed.). Plátano Edições Técnicas, Lisboa.

[18] José Augusto Silva Pontes Neto. 2006. Teoria da aprendizagem significativa de David Ausubel: perguntas e respostas. Série-Estudos-Periódico do Programa de Pós-Graduação em Educação da UCDB 21 (2006), 117-130.

[19] Teresa Cristina Rego. 2013. Vygotsky: uma perspectiva histórico-cultural da educação. Editora Vozes Limitada.

[20] Juan J Rodriguez, Nádia P Kozievitch, Silvia A Bim, Mariangela de OG Setti, Maria CFP Emer, and Marilia A Amaral. 2016. Uma proposta para apresentar a Computaç ao/Banco de Dados no Ensino Médio para o Publico Feminino. In Anais da XII Escola Regional de Informática de Banco de Dados (Londrina). SBC, Porto Alegre, RS, Brasil.

[21] Eduard Martí Sala and Javier Onrubia Gõni. 2000. As teorias da aprendizagem escolar. Artmed, Porto Alegre.

[22] Joseph J. Schwab. 1973. The Practical 3: Translation into Curriculum. The School Review 81, 4 (1973), 501-522. http://www.jstor.org/stable/1084423

[23] Geovana Silva, Giovanni Santos, and Vandor Rissoli. 2020. A Importância da Linguagem Nativa para a Aprendizagem Significativa em Lógica de Programação. In Anais do XXXI Simpósio Brasileiro de Informática na Educação (Online). SBC, Porto Alegre, RS, Brasil, 1803-1812. https://doi.org/10.5753/cbie.sbie.2020.1803
[24] Stela Silva, Angelica Calazans, and Bruno Magno da Silva. 2016. Construção e avaliação de um jogo educacional digital de Modelagem de Dados para o ambiente universitário. In Anais do XXIV Workshop sobre Educação em Computação (Porto Alegre). SBC, Porto Alegre, RS, Brasil, 41-50. https://doi.org/10.5753/wei.2016. 9647

[25] Toby J Teorey, Sam S Lightstone, Tom Nadeau, and HV Jagadish. 2013. Projeto e Modelagem de Banco de Dados: Tradução da 5 a Edição. Vol. 1. Elsevier.

[26] Lev Semenovich Vygotsky. 2000. A construção do pensamento e da linguagem. Martins Fontes, São Paulo.

[27] Robert K Yin. 2015. Estudo de Caso-: Planejamento e métodos. Bookman editora.

[28] Michael Young. 2014. Teoria do currículo: o que é e por que é importante. Cadernos de pesquisa 44, 151 (2014), 190-202.

[29] Árllon Lima, Marcos Diniz, and Marianne Eliasquevici. 2019. Metodologia 7Cs: Uma Nova Proposta de Aprendizagem para a Disciplina Algoritmos. In Anais do XXVII Workshop sobre Educação em Computação (Belém). SBC, Porto Alegre, RS, Brasil, 429-443. https://doi.org/10.5753/wei.2019.6648 